\title{
UNA LECTURA DE RAYUELA DESDE EL FANTASMA DE LA MAGA* A READING OF RAYUELA FROM MAGA'S GHOST
}

\author{
Natalia Plaza Morales \\ Université de Cergy-Pontoise
}

\begin{abstract}
RESUMEN
En el presente trabajo llevamos a cabo una lectura de Rayuela, con el propósito de profundizar en aquellos aspectos de estilo que nos resultan pertinentes en cuanto a la relación que mana entre los personajes de Horacio Oliveira y de La Maga en esta novela. En este sentido, pretendemos elucidar la caracterización de estos dos personajes por medio de la neutralidad como modo de lectura para comprender el juego narrativo cortazariano y reforzar la idea de una búsqueda de ruptura dicotómica en la narrativa del escritor argentino. El vínculo de Oliveira con las mujeres nos llevará a la lectura del goce como estado perseguido por el personaje.
\end{abstract}

PALABRAS CLAVES: juego, neutralidad, goce, ruptura, reconciliación.

\section{ABSTRACT}

In the present work we carry out a reading of Rayuela, with the purpose of deepening into those aspects of style which are relevant to us with respect to the relationship that springs between the characters of Horacio Oliveira and La Maga. In this sense, we intend to elucidate the portrayal of these two characters through neutrality as a reading hypothesis, in order to understand the narrative of Cortázar and reinforce the idea of a search for a dichotomous rupture in the narrative of the Argentine writer. Oliveira's bond with women will lead us to the reading of enjoyment as a state pursued by the character.

KEY WORDS: game, neutrality, pleasure, rupture-reconciliation.

Rayuela, escrita en 1963, se conoce como la segunda novela de Julio Cortázar, aquella que ha proporcionado al escritor argentino más fama en el ámbito internacional. Pocos amantes de la literatura no han oído hablar de la Maga, convertida ya en un personaje célebre de la literatura latinoamericana contemporánea, de la cual pretendemos ampliar aquí en detalle. De tal forma, nuestro análisis pretende desglosar

\footnotetext{
* Recibido: 26-12-2018 / Aceptado: 23-09-2019.
} 
algunas ideas de estilo que nos resultan significativas, principalmente aquellas que surgen del diálogo entre la Maga y Horacio Oliveira, una relación singular explorada por el escritor latinoamericano durante la primera parte de la novela.

Para algunos críticos, una de las lecturas más substanciales de esta novela nos conduciría a comentar su carácter lúdico y experimental, considerado como uno de los aspectos más distintivos que marcarían el hilo conductor de la narración. Así, como lo muestra ya su título, Rayuela evoca un juego para niños. En este sentido, algunos autores han analizado con acierto la importancia que Cortázar dio al gesto de jugar a lo largo de su obra: «El juego sería un pequeño mundo alternativo, un mundo propio a Oliveira, un lugar intermedio entre la realidad que huye y la que persigue, sin realmente pertenecer ya a ninguna de las $\operatorname{dos}^{1}{ } \gg$.

El propio Cortázar nos proporciona la pista para conectar sus declaraciones con las teorizaciones de otros autores que han concedido tal importancia a la actividad lúdica (Donald Winnicott, Sigmund Freud...). Y es que, tal y como lo explicaba Freud en El poeta y los sueños diurnos (1908), el juego del adulto nos permite adentrarnos en un universo paralelo, cercano al sueño, aquel del fantasmear despierto. Cortázar pensó en una rayuela para organizar la estructuración de su libro. Pero, además, tal juego ancestral se leería a lo largo de la novela como el símbolo que introduce una atmósfera metafísica, una búsqueda más sustancial de la existencia humana, esa que nos haría ir de «aquí» para «allá», es decir, de un mundo al otro. Esta puesta en marcha nos desvela la esencia limitada y, en gran sentido, surrealista de sus personajes, confirmando al lector su existir como un proceso absurdo e irrelevante, algo tan anodino como, en principio, podría parecer el juego de niños: «Cuando estaba escribiendo Rayuela, recordé que la rayuela es un mándala, sólo que los niños la juegan sin intención sagrada; entonces adopté la rayuela como símbolo de una tentativa metafísica, como búsqueda mítica que supone una iniciación y una $\operatorname{prueba}^{2}{ } »$.

Arrastrados por un aura metafísica para conformarse al mundo, los personajes de Rayuela brillan por su condición mediocre, tienen dificultades tanto económicas como sociales, viven en la más triste miseria parisina. Lo único que parece no hacerles cruzar la barrera de lo patético se descubre con respecto a la manera en que su universo los mantiene a flote: «Por ese entonces yo juntaba alambres y cajones vacíos en las calles de la madrugada y fabricaba móviles, perfiles que giraban sobre las chimeneas, máquinas inútiles que la Maga me ayudaba a pintar ${ }^{3}{ }^{3}$.

\footnotetext{
${ }^{1}$ Licata, Dinámica del círculo y de la espiral en Julio Cortázar: Una lectura de «Rayuela» a «Los Premios», Liège, Universidad de Liège, 2014, p. 43.

${ }^{2}$ Ibid., p. 14.

${ }^{3}$ J. Cortázar, Rayuela, Barcelona, Editorial Bruguera S.A, 1963, p. 12.
} 
El carácter ensayístico de la prosa cortazariana es aquel que conduce al escritor argentino a experimentar con la interrogación retórica, a empapar la escritura de una gran sensibilidad filosófica, crítica e humanística, la cual parecería regirse por la idea de hacernos evitar caer en una respuesta cerrada que podría interrumpir o poner fin al divagar del pensamiento en el que como lectores nos sumimos de pleno. El estilo de esencia surrealista y filosófica que se desglosa de los diálogos entre la Maga y Horacio nos servirá para formular la hipótesis de un posible modo de lectura, aquel que nos permitirá hablar en este trabajo de la recepción de una estética de lo neutro como espacio de reflexión en la experiencia escritural de Cortázar. Un lenguaje que interpretaremos por medio de la caracterización del personaje femenino, centrándonos fundamentalmente en la visión que se percibe de la forma en que dicho arquetipo convive y se representa ante los ojos de Horacio. El estudio del personaje femenino en Rayuela nos lleva a interpretar la relación que la Maga mantiene con el protagonista a través de una lectura narrativa del goce lacaniano, noción que nos conducirá a dar forma a algunas posibles cuestiones acerca del deseo experimentado por el personaje masculino.

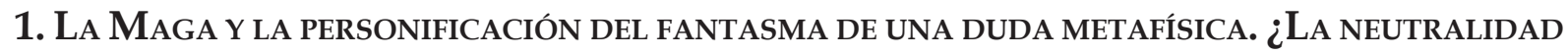 COMO ORDEN EN EL DESORDEN?}

«Yo quiero acabar con los sistemas y las relojerías para ver de bajar al laboratorio central y participar, si tengo fuerzas, en la raíz que prescinde de órdenes y sistemas ${ }^{4}$ » pronunciaba Cortázar en una de sus cartas, tras abandonar el cuento como escritura cerrada y lanzarse en la búsqueda de una forma diferente de escribir y de leer el texto. Lo que se propuso hacer Cortázar con este intento suyo de desestructurar cualquier orden, anunciaba ya algunos de los cimientos de un proceso estético que, creemos, va más allá de la organización textual y tiñe la literatura y a la sociedad contemporánea. Su manera de escribir en Rayuela, de representar metafísicamente a sus personajes, de indagar en el desorden como hito, nos llevará a formular su estilo como un precedente de una generación latinoamericana de escritores contemporáneos que juegan visiblemente con los procesos y términos antitéticos para romper con las dicotomías en su proceso de escritura, renovando una estética de vanguardia, entre quienes destacamos a Mario Bellatin y a César Aira.

Rayuela, protagonizada por un personaje masculino, Horacio Oliveira, ha destacado por la crítica por la fuerza con la que profundiza en la introspección de su personaje, quien se dibuja con distintas voces y tonalidades, presentándose al lector como un ser rico en facetas psicológicas:

${ }^{4}$ J. Cortázar, Cartas, Aurora Bernárdez y Carles Álvarez Garriga (eds.), Madrid, Alfaguara, 2012, p. 32. 
El narrador es, a veces, un Horacio discursivo, dialéctico, metafísico, con mucha sed, amargo, auto-inquisidor e inquisidor real pero con lágrimas en los ojos, viril de una manera desgarrada, desolada y noble, gauloise, lleno el pecho de humo y de ternura. Otras veces, el narrador es omnisciente, sujeto de ojo cruel, satírico, erudito, vomitoso, tercera persona entrometida, empeñada en empujar a Horacio al hoyo ${ }^{5}$.

A pesar de la importancia de su personaje masculino, este arquetipo sucumbe al encanto, a la fuerza hipnotizante del imaginario femenino de la Maga, quien al mismo tiempo podría leerse metafóricamente como un personaje esclarecedor para Horacio. Un ser que permite al lector observar en la psique de Horacio la existencia de una cortina que lo separa entre dos fronteras: sus propias limitaciones de pensamiento ante el género femenino y la puesta en marcha de un cuestionamiento de la neutralidad como interpretación del mundo. Una visión alternativa a la que el personaje parece abrirse gracias a la desgarradora identidad de la Maga, espíritu singular que se dibuja con garra a través de los ojos y de los pensamientos de su protagonista masculino. Horacio Oliveira aparece representado como un intelectual bohemio, un ser viviendo en una contradicción constante desencadenada por la disidencia entre sus propias acciones y aquellas protagonizadas por la Maga, personaje en principio presentado como antagónico al protagonista. Sin embargo, a través de las vivencias que el protagonista descubre de la mano de la Maga, podríamos pensar que los binarismos que rigen su mundo y su manera de pensar lo que le rodea aparecen cada vez menos marcados y definidos, de manera que percibimos dicha ruptura de dicotomías y de oposiciones, una desestabilización que no deja de evidenciarse en sus discursos. Tan sólo un aspecto nos hace volver a nuestro sistema de pensamiento occidental concebido en opuestos y apreciado en el discurso de Horacio: la delimitación entre los géneros. Esta barrera entre los sexos es aquella que permite a la Maga suponer que no puede comprender todo aquello que él y su círculo intelectual analizan. Se dibuja en el personaje femenino un cierto grado de estupidez y de inocencia, descrito como apego a una forma de vivir y a unas creencias singulares que conducen al propio Horacio a recordarse a sí mismo que su yo piensa y sabe demasiado como para disfrutar del instante presente:

Y así me había encontrado con la Maga, que era mi testigo y mi espía sin saberlo, y la irritación de estar pensando en todo eso y sabiendo que como siempre me costaba mucho menos pensar que ser [...]. Y por todas esas cosas yo me sentía antagónicamente cerca de la Maga, nos queríamos en una dialéctica de imán y limadura, de ataque y defensa, de pelota y pared ${ }^{6}$.

La ruptura de dicotomías en la obra de Cortázar es algo que ya había sido sugerido por la crítica: «Este rechazo de las dicotomías forma parte del grupo de ideas

\footnotetext{
${ }^{5}$ F. Alegría, «Rayuela: o el orden del caos», en J. Cortázar, Rayuela, Julio Ortega y Saúl Yurkievich (eds.), ALLCA xx, 1996, p. 721.

${ }^{6}$ J. Cortázar, Rayuela, Barcelona, Editorial Bruguera S.A, 1979, p. 13.
} 
que encuentran expresión a través de toda la obra de Cortázar ${ }^{7} \gg$. Recordemos que el pensamiento occidental se rige de manera binaria, se concibe en opuestos. Esta particularidad ha sido analizada por numerosos autores contemporáneos como Pierre Bourdieu y Françoise Héritier, entre otros.

Françoise Héritier fue una antropóloga francesa conocida por obras como El pensamiento de la diferencia (1996) y Masculino/ Femenino II. Disolver la jerarquía (2002). Según esta autora, pensamos el mundo en categorías de opuestos (arriba/ abajo, derecha/ izquierda...) y estas divisiones que lo caracterizan explican también las relaciones entre los sexos.

Para Pierre Bourdieu, el cuerpo se inscribe en una lógica convencional. Esta construcción social invita a pensar la oposición de sexos como una normalización que encuentra su justificación en una diferenciación anatómica, distinción ambicionada como natural y determinada. Sin embargo, Bourdieu sugiere que los cuerpos pueden redefinirse, incluso si tal transformación condujera a remodelar toda una serie de mecanismos ya consolidados, considerando los atributos de lo masculino bajo un ángulo positivo y dominante con referencia a las carencias y a las condiciones femeninas. El sociólogo sostiene que el cuerpo permanece todavía siendo un campo de experimentación limitado, mediante el cual, existiría una interacción subjetiva entre la identidad del sujeto y el otro, en tanto que agente perceptivo. Bourdieu atribuye esta oposición a un producto social, el cual explicaría la experiencia limitada del cuerpo femenino, inscrito en un sistema interactivo de percepción/ recepción: «Estos esquemas en los cuales un grupo deposita sus estructuras fundamentales (como grande/pequeño, fuerte/débil, grueso/fino, etc.) se interponen desde el principio entre cualquier agente y su cuerpo ${ }^{8}$ ».

En esta línea de pensamiento, podríamos decir que a menudo la crítica ha analizado a los personajes de la Maga y de Oliveira como opuestos. «El otro» sería la mujer, perteneciente a un grupo periférico, la ignorante en el caso de Lucía o la Maga. Mientras que Horacio correspondería al intelectual, a quien domina y dirige sus encuentros. Pero al pensar la relación con la Maga y hacerla contar a través del yo de Horacio, el escritor argentino nos dejaría apreciar una lectura de lo neutro cercana a la noción filosófica bartesiana con estas caracterizaciones. Lo neutro leído como un intervalo que no es ni el intelectual ni la ignorante, ni la razón ni la locura, sino más bien el tránsito que une estas diferencias y las deja mirarse de frente, de manera que, en la misma línea de análisis señalada por Malva E. Filer, el personaje masculino de

\footnotetext{
${ }^{7}$ M. E. Filer, «Leer a Cortázar como mujer» en Me gustas cuando callas... Los escritores del 'Boom' y el género sexual, Puerto Rico, Universidad de Puerto Rico, 2002, p. 68.

${ }^{8}$ P. Bordieu, La dominación masculina, Barcelona, Anagrama, 1999, p. 83.
} 
Rayuela nos permite situarnos en ese espacio que busca precisamente romper con estas dicotomías y reconciliarlas ${ }^{9}$.

Para entender mejor la idea de lo neutro a la que nos referimos, es interesante remitirnos brevemente a las teorizaciones de Barthes. La reflexión de Barthes sobre lo neutro contiene un matiz filosófico. Su objeto de estudio tiene como pretensión general la ambición de disolver el carácter antinómico y binario del pensamiento occidental. Lo neutro es este estado de placer estético en la escritura. Con esta noción, Barthes ambiciona una especie de deconstrucción del pensamiento antitético de nuestra cultura occidental, interesándose en la desincronización de binarios y de binarismos. Así pues, lo neutro en Barthes designa una intención de traspasar las oposiciones ${ }^{10}$.

A nivel de la significación, no se trataría de buscar el sentido de lo neutro en la palabra, habría que buscarlo en el discurso mismo. Esta categoría nos conduce a renunciar al sentido literal y a llevarnos hasta un nivel de entendimiento más complejo y alejado de nuestra percepción y del pensamiento occidental. Esto produce una apertura de significación, otra lógica que es externa a lo que «es dicho» en el texto o en el habla. No se trata de considerar lo neutro como un tercer término sino como el segundo término de un nuevo paradigma capaz de ir más allá de lo que es comprensible por el pensamiento:

Lo Neutro no es pues el tercer término -el grado cero -de una oposición a la vez semántica y conflictiva; es, en un eslabón distinto de la cadena infinita del lenguaje, el segundo término de un nuevo paradigma, del cual la violencia (el combate, la victoria, el teatro, la arrogancia) es el término pleno ${ }^{11}$.

Es notablemente hacia el sentido filosófico que orientamos la caracterización de los personajes protagonistas de Rayuela, la Maga y Horacio Oliveira. La Maga no sabe de delimitaciones. Ella parece mirar a través de otros ojos, de unos anteojos que no necesitan alimentarse con información superflua, como lo sugiere el propio Horacio: «No aprendas datos idiotas - le aconsejaba - . Por qué te vas a poner anteojos si no los necesitas» (23). Cierto, la Maga no posee los conocimientos metafísicos que tienen los otros personajes masculinos, pero es precisamente esto lo que hace que ella pueda ver el mundo desde una óptica que, para Oliveira, con tanto como ha leído y aprendido, le resulta imposible. Y así, podríamos sugerir cómo esta falta del orden epistemológico permitiría a la Maga defenderse de caer en una visión organizada del mundo: «Era insensato querer explicarle algo a la Maga. Fauçonnier tenía razón, para gentes como ella el misterio empezaba precisamente con la explicación. La Maga oía hablar de

\footnotetext{
${ }^{9}$ M. E. Filler, «Leer a Cortázar como mujer», ob. cit., p. 68.

${ }^{10}$ R. Barthes, Lo neutro. Cursos y Seminarios en el Collège de France, Siglo XXI, 2004, p. 85.

${ }^{11}$ R. Barthes, Roland Barthes por Roland Barthes, Barcelona, Kairos, 1978, p. 141.
} 
inmanencia y trascendencia y abría unos ojos preciosos que le cortaban la metafísica a Gregorovius $^{12} \gg$.

Horacio admite la admiración proferida a la Maga, un reconocimiento que surge precisamente en relación con la forma en que ve el mundo. La Maga es capaz de proyectarse en cada una de las cosas de la vida, es actriz de todo lo que le acontece y le rodea. Es un ser experimental y no metafísico, quien carece de un orden de pensamiento, y por ello, podemos pensar que actúa desmarcándose de la razón como sistema para comprender el mundo: «Feliz de ella que podía creer sin ver, que formaba cuerpo con la duración, el continuo de la vida. Feliz de ella que estaba dentro de la pieza, que tenía derecho de ciudad en todo lo que tocaba y convivía, pez río abajo, hoja en el árbol, nube en el cielo, imagen en el poema. Pez, hoja, nube, imagen: exactamente eso, a menos $q^{13} \mathrm{e}^{13} \ldots{ }^{\prime}$. A pesar de su ignorancia, de parecer estar siempre a un nivel inferior en comprensión que Horacio, la Maga también tiene buenos argumentos para cuestionar la visión del mundo de éste: Horacio parece planificar todo, examinar cada detalle, hasta el punto de que tal rigurosidad le llevará a dejar escapar el encanto inmediato de las cosas. De esta forma, lo «racional» y lo «irracional» parecen ir perdiendo con el discurso de la Maga su carácter fuertemente opuesto:

- Yo creo que te comprendo - dijo la Maga, acariciándole el pelo-. Vos buscás algo que no sabés lo que es. Yo también y tampoco sé lo que es. Pero son dos cosas diferentes. (...) ¿Y no se te ha ocurrido sospechar que detrás de ese Mondrian puede empezar una realidad Vieira da Silva? (...) Tenés miedo, querés estar seguro. No sé de qué... Sos como un médico, no como un poeta ${ }^{14}$.

Y así, a través de la visión de un personaje torpe, poco ilustrado, pero a su vez peculiar, como se presentaría la Maga ante Horacio, se podría contemplar un intento del escritor argentino por materializar, por medio de la escritura, una manera de pensar más allá de los límites: un desorden buscado a través de la caracterización de su personaje femenino que intenta «sobrevivir» con dicha ruptura del orden convencional. En este sentido, la Maga se nos descubre como un personaje extraordinario, el conducto del deseo al que el protagonista se halla en cierto modo atado, dejando trasparentar en sí misma un estado en confrontación que le hace ver el mundo desde la melancolía y la distancia.

Pero además, la Maga es el espejo contrariado gracias al cual el personaje masculino se cuestiona directamente sobre las sensaciones de ausencia y de carencia del instante presente en el que vive, por el que se halla preso en una espiral en continua

\footnotetext{
${ }^{12}$ J. Cortázar, Rayuela, Barcelona, Editorial Bruguera, 1979, p. 23.

${ }^{13}$ Ibid., p. 19.

${ }^{14}$ Ibid., p. 64.
} 
repetición de acciones y de pensamientos, sumido en un estado de pesadumbre y de desencanto, un momento del que no es capaz de disfrutar sin buscar una razón lógica, un por qué a toda acción : « Pero detrás de toda acción había una protesta, porque todo hacer significaba salir de para llegar a, o mover algo para que estuviera aquí y no allí, o entrar en esa casa en vez de no entrar o entrar en la de al lado, es decir que en todo acto existía la admisión de una carencia, de algo no hecho todavía ${ }^{15}$ ».

Por su parte, la Maga es puro desorden, un personaje capaz de pasar de un extremo al otro, de la alegría desenfrenada a la tristeza más infinita. La metáfora del paraguas mojado que se cierra de repente, describe a la Maga como a alguien que, de un momento al otro, cambia su energía y la convierte en melancolía. La Maga es permeable, al igual que el paraguas que aguanta la lluvia sin romperse, pero que, aún mojado, se pliega sin más dilación: «Oh Maga, en cada mujer parecida a vos se agolpaba como un silencio ensordecedor, una pausa filosa y cristalina que acababa por derrumbarse tristemente, como un paraguas mojado que se cierra ${ }^{16}{ }$.

La virtud de la Maga es precisamente la de dar rienda suelta a este desorden de acciones y de pensamiento como una determinación natural de su carácter, una forma de sentir que encamina a Horacio a poner en tela de juicio sus esquemas de pensamiento concebidos en oposición y, a cuestionar deshacerse de estos: «Todo desorden se justificaba si tendía a salir de sí mismo, por la locura se podía acaso llegar a una razón que no fuera esa razón cuya falencia es la locura. «Ir del desorden al orden», pensó Oliveira. «Sí, ¿pero qué orden puede ser ése que no parezca el más nefando, el más terrible, el más insanable de los desórdenes ${ }^{17}$ ?».

La duda existencial y metafísica es aquella que acompaña a un personaje acongojado por perderse en un bucle pensamiento que le hace verse atrapado en una serie de cuestionamientos y de condiciones que no solucionan para nada su vida de mediocridad. El juego del orden y del desorden, la locura y la razón, van entrelazándose en la comunicación de esta pareja de personajes que se buscan para encontrarse, lo que nos lleva a la hipótesis de la neutralidad como el descifrar metafísico de un laberinto de ideas contrapuestas, de conflictos en oposición, como lo son tradicionalmente el instinto y la reflexión:

Entre cebar el mate y que se lo cebara la Maga no había duda posible. Pero todo era escindible y admitía en seguida una interpretación antagónica: a carácter pasivo correspondía una máxima libertad y disponibilidad, la perezosa ausencia de principios

\footnotetext{
$\overline{{ }^{15} \text { Ibid., pp. 16-17. }}$

${ }^{16}$ Ibid., p. 6.

${ }^{17}$ Ibid., p. 63. 
y convicciones lo volvía más sensible a la condición axial de la vida (lo que se llama un tipo veleta $\left.{ }^{18}\right)$.

El juego es precisamente ese canal, el instrumento que permite, metafísicamente pensando, llevarnos hacia un mundo paralelo, en el que todas estas contradicciones y todos estos opuestos parecen perder sus significaciones primeras:

El juego sería un pequeño mundo alternativo, un mundo propio a Oliveira, un lugar intermedio entre la realidad que huye y la que persigue, sin realmente pertenecer ya a ninguna de las dos. En su desconcierto, el territorio lúdico le otorgaría una especie de colocación temporaria. ${ }^{19}$

Y es durante el juego amoroso, como veremos a continuación, que las pulsiones de Horacio presentan una mayor versatilidad, que se marcan los instintos y se lee una armonía entre dimensiones que nos han sido representadas como opuestas.

\section{El GOCE DE HoRACIO Y EL IMAGINARIO FEMENINO}

El personaje de Horacio vive en un estado de búsqueda y de rechazo amoroso que se refleja en la historia que tiene con la Maga. Como hipótesis, podríamos formular que dicha controversia pulsional es la que nos permitiría hablar de una escritura que nos acerca al sentimiento del goce, uno de los aspectos fundamentales que marca una forma de sentir que es propia del protagonista de la novela de Cortázar. Horacio parece transmitir la ausencia, la falta, la carencia y el deseo, como las sensaciones que marcan la relación entre ambos.

Horacio describe a la Maga como una amante desenfrenada, con una gran autonomía sexual:

Se daba entonces como una bestia frenética, los ojos perdidos y las manos torcidas hacia adentro, mítica y atroz como una estatua rodando por una montaña, arrancando el tiempo con las uñas, entre hipos y un ronquido quejumbroso que duraba interminablemente ${ }^{20}$.

Pero cuando Lucía o la Maga «despierta» de este estado de frenesí en el que goza de placer, necesita recurrir a Oliveira para que la acaricie y la abrace, para poder sobrellevar la vuelta a la realidad, convirtiéndose para Horacio en un ser dócil y dependiente: "Pero la Maga sufría de verdad cuando regresaba a sus recuerdos y a todo lo que oscuramente necesitaba pensar y no podía pensar, entonces había que besarla profundamente, incitarla a nuevos juegos, y la otra, la reconciliada ${ }^{21}$ ». La Maga

\footnotetext{
${ }^{18}$ Ibid., p. 331.

${ }^{19}$ Licata, Dinámica del círculo y de la espiral, ob. cit., p. 43.

${ }^{20}$ J. Cortázar, Rayuela, ob. cit., p. 25.

${ }^{21}$ Ibid., p. 25.
} 
acaba transformada en una fuente suprema de deseo, sus almas, sus intelectos no pueden conciliarse, pero sí sus cuerpos. Es en el ámbito del placer donde la Maga se convierte en un ser que pierde, ante Horacio, sus características inferiores genéricas y presenta un gran dominio y control de su ser.

Pero, aunque los personajes se atraen como «imanes», Horacio parece convencerse de que dicho deseo fluye porque no hay un sentimiento de amor entre ellos: «Puesto que no la amaba, puesto que el deseo cesaría (porque no la amaba, y el deseo cesaría), evitar como la peste toda sacralización de los juegos ${ }^{22} \gg$. El personaje masculino decide poner fin a su relación con la Maga e irse del apartamento de esta. Esto ocurre en el momento en que los lazos afectivos entre ambos parecen estrecharse (la Maga le pide que vayan a vivir juntos). Nuestra interpretación de lectura es que Horacio debe distanciar esta relación para conservar la espiral del goce marcada por la ausencia y por el rechazo. Es así como Horacio se va con Pola, para repetir con ella este instante del goce que ya había vivido con la Maga, y evitar así que el deseo se materialice, que desaparezca entonces el dolor y la inquietud propios que acompañan al estado del goce: «Había pasado de la Maga a Pola en un solo acto, sin ofender a la Maga ni ofenderse, sin molestarse en acariciar la rosada oreja de Pola con el nombre excitante de la Maga. Fracasar en Pola era la repetición de innúmeros fracasos ${ }^{23}$ ».

Recordemos que para Lacan el goce no es el deseo. Mientras que el deseo tiene que ver con la pérdida del objeto (en el caso de Rayuela hablaríamos de la Maga), el goce se asociaría con el significante. Para Lacan, y siguiendo a Freud que ya habló del lenguaje de los sueños, el inconsciente es un sistema de lenguaje que se organiza como un conjunto de significantes. Los significantes o imágenes actúan en la cadena paradigmática por desplazamiento, a través de la metonimia, y nos conducen al deseo como la fuerza de dominación. Si seguimos las teorizaciones del psicoanalista francés, el significante en Rayuela se correspondería con la imagen mental que el protagonista tiene del género femenino, de manera que todas las mujeres (Pola, la Maga, Talita...) se organizarían en un mismo proceder para permitir que el protagonista pueda experimentar el cuerpo en el sentido lacaniano:

Pues lo que yo llamo goce, en el sentido que en el cuerpo se experimenta, es siempre del orden de la tensión, del forzamiento, del gasto, incluso de la hazaña. Incontestablemente hay goce en el nivel donde comienza a aparecer el dolor, y sabemos que es sólo a ese nivel del dolor que puede experimentarse toda una dimensión del organismo que de otro modo aparece velada [...] Este cuerpo no se caracteriza simplemente por la dimensión de la extensión: un cuerpo es algo que está hecho para gozar, gozar de sí mismo²4.

\footnotetext{
${ }^{22}$ Ibid., p. 25.

${ }^{23}$ Ibid., p. 334.

${ }^{24}$ J. Lacan, Psicoanálisis y Medicina, p. 17. 
En esta línea de análisis, el protagonista no dudará en repetir los mismos rituales que emprendió con la Maga, llevando a Pola al mismo hotel, demostrando que el objeto de deseo es indiferente, así como el lugar y el momento en el que se encuentre con estas mujeres:

Por eso llevó a Pola al mismo sitio hotel de la rue Valette, encontraron a la misma vieja que los saludó comprensivamente, qué otra cosa se podía hacer con ese sucio tiempo. Seguía oliendo a blando, a sopa, pero habían limpiado la mancha azul en la alfombra y había sitio para nuevas manchas ${ }^{25}$.

Esta búsqueda de la mujer que lleva a cabo Horacio (en Talita, en la Maga, en Pola...), podría leerse como la repetición constante del goce, del significante del cuerpo de mujer que el protagonista busca una y otra vez, y que le llevan al sentimiento de lo absurdo:

Pola París, Pola París, cada vez más suya, senos sin sorpresa, la curva del vientre exactamente recorrida por la caricia, sin el ligero desconcierto al llegar al límite antes o después, boca ya encontrada y definida, lengua más pequeña y más aguda, saliva más parca ${ }^{26}$.

Al evitar la consolidación del amor, el personaje prolonga el deseo, y al cambiar de significante, Horacio se asegura mantener viva la potencia del goce, para experimentar con intensidad el dolor y la tensión de la pulsión:

Amor mío, no te quiero por vos ni por mí ni por los dos juntos, no te quiero porque la sangre me llame a quererte, te quiero porque no sos mía, porque estás del otro lado, ahí donde me invitás a saltar y no puedo dar el salto, porque en lo más profundo de la posesión no estás en mí, no te alcanzo ${ }^{27}$.

Pola podría interpretarse como una prolongación del significante de la Maga. Acompaña a Horacio cuando la Maga ya no está, recordándonos que el goce es la marca perseguida por el propio personaje, quien no quiere librarse al amor para continuar con la satisfacción dolorosa de la carencia:

Pola levantó un poco la cabeza y miró a Horacio que tenía los ojos cerrados. Se preguntó si también haría eso con su amiga, la madre del chico. A él no le gustaba hablar de la otra, exigía como un respeto al no referirse más que obligadamente a ella ${ }^{28}$.

\footnotetext{
${ }^{25}$ J. Cortázar, Rayuela, ob. cit., p. 334.

${ }^{26}$ Ibid., pp. 335-336.

${ }^{27}$ Ibid., p. 337.

${ }^{28}$ Ibid., p. 359.
} 
En este sentido, es como si los personajes femeninos de Pola y la Maga comprendiesen al final que la conexión con Horacio no puede ir más allá del goce y reconociesen y aceptasen la sombra de estos otros significantes de deseo:

Hasta cuando gemía, porque en un momento había gemido, había querido librarse pero ya era demasiado tarde, el lazo estaba cerrado y su rebelión no había servido más que para ahondar el goce y el dolor, el doble malentendido que tenían que superar porque era falso, no podía ser que en un abrazo, a menos que sí, a menos que tuviera que ser así $^{29}$.

La Maga, por su parte, ya había admitido y aceptado la relación con Pola, aunque en ella se dibuje este sentimiento de amor que le lleva al reproche: «París es gratis - citó la Maga - . Vos lo dijiste el día que nos conocimos. Ir a ver la clocharde es gratis, hacer el amor es gratis, decirte que sos malo es gratis, no quererte... ¿Por qué te acostaste con Pola ${ }^{30}$ ?».

En un momento de la historia con la Maga, el protagonista parece llegar a reconocer que el amor ha surgido entre ambos y que entonces es necesario poner fin a sus encuentros. Horacio es capaz de admitir que ha querido a la Maga, que ha traspasado esta frontera desde el deseo, hasta el punto de caer en un estado vacío y cerrado, en un círculo que ya no permite el juego de la búsqueda, aquel ritmo tan espontáneo que marcaba su relación: «Querer a la Maga había sido como un rito del que ya no se esperaba la iluminación; palabras y actos se habían sucedido con una inventiva monotonía, una danza de tarántulas sobre un piso lunado, una viscosa y prolongada manipulación de $\operatorname{ecos}^{31}$ ».

Uno de los pasajes de Rayuela nos permitirá hablar de una posible lectura de la metáfora del final del goce, puesto que podríamos interpretar que, aunque Horacio piensa que la Maga espera la muerte como un verdadero encuentro intelectual, la muerte del amor también podría leerse como el final del goce, puesto que para Lacan el goce no termina nunca si no es tras la muerte: «Se llegó así a saber que la Maga esperaba verdaderamente que Horacio la matara, y que esa muerte debía ser de fénix, el ingreso al concilio de los filósofos [...] la a única posibilidad de encuentro estaba en que Horacio la matara en el amor ${ }^{32} \gg$.

La Maga y Horacio a veces se dejan arrastrar hacia el lado más destructivo del deseo y se arrancan en una tendencia instintiva que pone de manifiesto las pulsiones mortíferas de los dos personajes: « Donde ella podía conseguir encontrarse con él, en el

\footnotetext{
${ }^{29}$ Ibid., p. 359.

${ }^{30}$ Ibid., p. 366.

${ }^{31}$ Ibid., p. 344.

${ }^{32}$ Ibid., p. 26.
} 
cielo de los cuartos de hotel se enfrentaban iguales y desnudos y allí podía consumarse la resurrección del fénix después que él la hubiera estrangulado deliciosamente [...] como si empezara a reconocerla, a hacerla de verdad suya, a traerla de su lado ${ }^{33}$ ».

\section{Luces y sombras de un mismo espejo: la Maga y Oliveira}

A pesar de la visión machista que rodea al personaje de la Maga, Horacio no puede dejar de pensar en la Maga como un personaje puro, distinto, capaz de obviar cualquiera de las necesidades y los cuestionamientos filosóficos y vitales que le ahogan. La Maga no sería, según nuestra lectura, la antítesis de Horacio, sino el más allá de lo material y lo pensable, lo abstracto de un pensamiento de lo absurdo, surrealismo puro. El lector lograría pensar el arquetipo femenino desde la perspectiva deconstruccionista, de manera que tan sólo este personaje encontraría su binaridad convencional en el género, una distinción de la que el escritor argentino pareció no saber o querer deshacerse.

Horacio se mira y mira a la Maga, y para pensarla como distinta a él, parece no saber más que oponerla, cuando en realidad la Maga es representada como más que un pensamiento que ya ha pasado el filtro de la normatividad, la Maga es puro sueño surrealista. La Maga puede amar a su hijo, cuidarlo y llorarlo, al tiempo que lo rechaza, segundos después, de la manera más incoherente:

Horacio tiene razón, no me importa nada de ti a veces, y creo que eso me lo agradecerás un día cuando comprendas, cuando veas que valía la pena que yo fuera como soy. Pero lloro lo mismo, Rocamadour, me equivoco, porque a lo mejor soy mala o estoy enferma o un poco idiota, no mucho, un poco pero eso es terrible ${ }^{34}$.

La Maga es un personaje que dirige sus actos de manera opuesta a como se nos ha enseñado. Sin embargo, esta forma de actuar es tan espontánea, que a Horacio y al lector les resulta difícil juzgar tal pensamiento como captivo o inmoral, llegando a la conclusión de que existe en la Maga una forma de pensar distinta que no se corresponde con nuestra visión del mundo. Así, por ejemplo, la Maga se escandaliza al hablar alto por si despierta su hijo enfermo, pero no parece asustada o aterrorizada por tener a su hijo moribundo en casa y no en el hospital. Y Horacio parece observar con asombro y, desde lo racional, la manera extraña con la que actúa esta mujer que le tiene asombrado y atrapado, que le lleva quizás a poder materializar la noción más disparatada de sus ideas, ¿y si aquello que rigiese nuestros pensamientos fuese lo irracional? ¿O y si no

\footnotetext{
${ }^{33}$ Ibid., p. 26.

${ }^{34}$ Ibid., p. 152.
} 
pudiésemos distinguir entre lo que es racional y lo que no? ¿Encontraría a la Maga ${ }^{35}$ ? O lo que es igual, ¿descubriría una forma diferente de ver y de pensar el mundo?

Los personajes femeninos analizados en este trabajo son el producto del imaginario femenino pensado por el escritor argentino. La Maga no es tan sólo un personaje encantador e idílico, sino que, además, marca ya una forma de sentir al ser humano contemporáneo: defectuoso, débil, torpe pero singular, libre y atrevido. Lo que le gusta a Oliveira de la Maga son precisamente sus defectos, su peculiar forma de ver el prisma desde un lado no contrariado, y por qué no, de reinventar el espejo, de neutralizar estos opuestos para poder ser feliz a pesar de lo miserable de su vida.

Cualquiera de los elogios que recibe la Maga, ella misma los traslada a Horacio. Y al final, la metáfora es aquella de una luz, la Maga, perseguida por una sombra, Horacio, o la de una sombra perseguida por una luz, la Maga:

Gregorovius la contempló extasiado, acordándose de una calle de Morlaix al anochecer, un viaducto altísimo, nubes. - Esa luz es tan usted, algo que viene y va, que se mueve todo el tiempo.

- Como la sombra de Horacio - dijo la Maga-. Le crece y le descrece la nariz, es extraordinario ${ }^{36} \gg$.

El propio Horacio parece reconocer que tiene miedo de encontrar en ella una parte de sí mismo, como si la búsqueda y el encuentro continuado de la Maga no fuera más que una persecución y una huida de su otro yo, aquel que permanece escondido pero que en realidad tanto le asombra: «Nunca te llevé a que madame Leoni te mirara la palma de la mano, a lo mejor tuve miedo de que leyera en tu mano alguna verdad sobre mí, porque fuiste siempre un espejo terrible, una espantosa máquina de repeticiones ${ }^{37}{ }$.

Estos personajes comparten la esencia de ser seres fatídicos, con vidas mediocres y miserables:

A la Maga le encantaban los líos inverosímiles en que andaba metida siempre por causa del fracaso de las leyes en su vida. [...] Por mi parte [...] no encontraba demasiado horrible que al entrar en un cuarto a oscuras para recoger un álbum de discos, sintiera bullir en la palma de la mano el cuerpo vivo de un ciempiés gigante ${ }^{38}$.

\footnotetext{
${ }^{35}$ Ibid., p. 6.

${ }^{36}$ Ibid., p. 37.

${ }^{37}$ Ibid., p. 7.

${ }^{38}$ Ibid., pp. 9-10. 
La Maga es además un ser extraño, supersticiosa, capaz de creer que tal destino puede troncarse por tan solo un gesto anodino. Esto es algo en lo que coincide con el propio protagonista:

En fin, no es fácil hablar de la Maga que a esta hora anda seguramente por Belleville o Pantin, mirando aplicadamente el suelo hasta encontrar un pedazo de género rojo. Si no lo encuentra seguirá así toda la noche [...] Sé lo que es eso porque también obedezco a esas señales, también hay veces en que me toca encontrar trapo rojo ${ }^{39}$.

Estamos ante personajes que yacen en la penuria y que, precisamente, por la elegancia con la que viven tal oscuridad, brillan como seres extraordinarios: «Por ese entonces yo juntaba alambres y cajones vacíos en las calles de la madrugada y fabricaba móviles, perfiles que giraban sobre las chimeneas, máquinas inútiles que la Maga me ayudaba a pintar ${ }^{40}{ }_{\gg}$.

Terminemos nuestro análisis con una cita de Fernando Alegría, quién no duda en poetizar la complejidad de los personajes. Porque la Maga puede ser todo: la vida, la muerte, la razón, la locura. Al borrar cada gesto, cada acción, cada término, la Maga nos lleva hasta Horacio, hacia el otro lado, aquel que no tiene más escapatoria que saltar al vacío para reencontrarse consigo mismo:

¿Quién vive? La Maga. Quien vive es, en verdad, quien se hunde, agoniza y muere en la locura que es nuestra suerte, quien se da sin pedir nada, en el acto del amor. ¿Quién muere? La Maga, porque no se vive de regalo y hay que pagar el precio [...] No hay, entonces, otro camino para el desesperado auténtico que desgarrarse las vestiduras, de adentro y de afuera, llorando de amor por el mundo que borra de una plumada o de un salto. Horacio ${ }^{41}$.

\section{Bibliografía}

Alegría, F., «Rayuela: o el orden del caos», en Julio Cortázar, Rayuela, eds. Julio Ortega y Saúl Yurkievich, ALLCA xx, 1996.

BARTHES, R., Roland Barthes por Roland Barthes, Barcelona, Kairos, 1978.

, Lo neutro. Cursos y Seminarios en el Collège de France, Madrid, Siglo XXI, 2004.

Bourdieu, P., La dominación masculina, Barcelona, Anagrama, 2000.

Cortázar, J. (1955-64), Cartas, Edición de Aurora Bernárdez y Carles Álvarez Garriga, Madrid, Alfaguara, 2012. (1963), Rayuela, Barcelona, Editorial Bruguera S.A, 1979.

\footnotetext{
${ }^{39}$ Ibid., p. 10.

${ }^{40}$ Ibid., p. 12.

${ }^{41}$ F. Alegría, Rayuela: o el orden del caos, ob. cit. p. 772.
} 
Natalia Plaza Morales

FILER, M. E., «Leer a Cortázar como mujer», en Me gustas cuando callas... Los escritores del 'Boom' y el género sexual, Puerto Rico, Universidad de Puerto Rico, 2002.

Héritier, F., Masculino/ Femenino. El pensamiento de la diferencia, Barcelona, Ariel, 2002. , Masculino/ Femenino II. Disolver la jerarquía, México, FCE, 1998.

Licata, Dinámica del círculo y de la espiral en Julio Cortázar: Una lectura de Rayuela a Los Premios, Liège, Universidad de Liège, 2014.

LACAN, J., Les quatre concepts fondamentaux de la psychanalyse. Le Séminaire, Livre XI, Paris, Du Seuil, 1964.

, Le désir et son interprétation, Livre VI, Paris, De la Martinière, 1958-1959.

Psicoanálisis y Medicina. Disponible en https://www.lacanterafreudiana.com. ar $/ 2.5 .1 .9 \%$ 20\% 20\% 20PSICOANALISIS\%20Y\%20MEDICINA,\% 201966.pdf [Consultado 26-11-2018]. 